\title{
Research on Management Information Platform of County agricultural products electronic commerce Based on Precision Poverty Alleviation
}

\author{
Chunhua $\mathrm{Hu}^{1, *}$, Ling Yang ${ }^{2}$ \\ ${ }^{1}$ School of Management of Wuhan Donghu University, Hubei Province, China \\ ${ }^{2}$ Wuhan Electric Power Technical College, Hubei Province, China \\ *600690@163.com
}

\begin{abstract}
Accurate poverty alleviation is an innovative means of poverty alleviation, and provides a new way for the work of poverty alleviation. Production of agricultural products for the life of the peasants provide material guarantee, the need to take active measures to give support, allowing farmers to increase production to achieve, to create favorable conditions for the poverty alleviation work and promoting the county agricultural products e-business process, promotes development of the countryside. Management information collaboration platform is the basic need of the county agricultural product electronic commerce management, and it is the important guarantee of the safety value, efficiency value and cost value realization of the county agricultural product electronic commerce. In accurate poverty alleviation foundation, this paper analyzes the county agricultural products e-commerce management information platform construction of the status quo, discusses the key focus and construction planning of the county agricultural products e-commerce management information platform.
\end{abstract}

Keywords: Precision poverty alleviation; Agricultural product electronic commerce; Management informatization; Informatization construction; Collaboration platform.

\section{Introduction}

Accurate poverty alleviation is a pointer to the different poverty areas of the environment, the situation of different poor farmers, the use of compliance and effective procedures for the implementation of the poverty alleviation object accurate identification, precise helping, and precise management of governance. Rural development is relatively backward, farmers' income lags behind urban residents, and the population that has not been out of poverty is mainly concentrated in rural areas. In the rural areas to promote the precision of poverty alleviation. When the electronic commerce in the agricultural products meets, formed agricultural e-commerce, e-commerce as the carrier of ecological system of agricultural products is entering a new agricultural product, the rapid development of electronic commerce industry, especially application of mobile electronic commerce popularization, smart devices and sensors e-commerce products in agricultural products, make agricultural production more customized and intelligent. Based on the transparency of information of agricultural products e-commerce, improve the traditional agricultural products industry chain and information asymmetry, changed the traditional agricultural products high transaction costs and trading links long adverse, thus for agricultural products brought giant value-added space. By way of electronic commerce, both distributed between farmers and individualized consumption docking, can also be implemented in a decentralized intensive management of farmers, mutual business and agricultural products of best practice in the fast spreading and sharing, through the electronic commerce can all reduce the transaction costs. Based on the essential characteristics of the e-commerce of agricultural products, when the combination of agricultural products and e-commerce can reduce the information asymmetry, reduce transaction costs, the "three rural" real information to show in front of consumers, farmers can not only realization of agricultural products e-commerce exhibition and promotion, but also through e-commerce procurement of agricultural products, improve production efficiency to achieve precise poverty. 


\section{Construction of Management Information Platform of County Agricultural Products Electronic Commerce Based on Precision Poverty Alleviation}

Before the 90s of the 20th century, agricultural e-commerce information management to logistics automation of the initial stage of development, the "Tenth Five Year" and "Eleventh Five Year" period to access to the agricultural product electronic commerce information management for the center of gravity of the rapid development stage. At present, the e-commerce of agricultural products has full access to information management platform construction stage, and gradually expand the application field of information technology, from the operation of the electronic commerce system of agricultural products, management and operations to a link for each management are melting into the information technology. The popularization of information technology has been developed from the management application stage of logistics automation as the center to the application stage based on the construction of management information platform ${ }^{[1]}$.

In the "Eleventh Five Year" period, some agricultural products e-commerce began to implement "unified organization, the pilot first, typical design, step-by-step promotion" information management

${ }^{[2]}$, which is the rapid development of the construction of management information, it can promote the management informationization construction toward the integration and optimization of unified centralized direction and management information from the original slice segmentation department level, enterprise level steering through vertical and horizontal integration of agricultural products e-commerce level.

At present, many agricultural products in our country have been or are being established to cover the enterprise, local integration of agricultural products e-commerce management information system, management information platform construction has been further promoted.

\subsection{Need to Further Expand the Scope of Information Resources}

To cope with the e-commerce of agricultural products at all levels is not in place, data model of a lack of unified standard, master data management is not in place, all kinds of logistics business between still exist a large degree of data barriers, co-ordinate the use of the degree is relatively shallow, relatively high cost and difficulty of operation, resource utilization rate relatively low, and these need to further improve.

\subsection{Management Information Platform Needs to be Further Enhanced}

The agricultural product electronic commerce management information platform has been built basically can meet the management needs of the asset business, but still need to be further improved according to the principles of management. With the extensive use of logistics data acquisition system, the storage capacity of data center and the ability of information network transmission need to be further expanded. In order to promote the integration of business applications and processes, it is very important to enhance the ability of information processing, data exchange and processing of the management information platform. Only by constantly improving and perfecting the management information platform, can we make the management information system of agricultural products in our country safe and stable operation.

\subsection{Analysis of Decision-Making Ability and Business Applications Need to be Further Improved}

At present, analysis and decision-making ability is still in a relatively early stage of report query and data acquisition. In business layer, operation layer, strategic decision analysis layer and intelligent degree also need further improvement; and business applications currently in immature stage, with further improvement in update management mode, organization structure reform, business process, between the various applications also in constantly put forward new demands and new requirements, resulting in existing business application system becomes very does not adapt, even has been unable to support the original situation. Therefore, the business application should be in accordance with the logistics value chain to gradually complete the integration of the whole process deeper.

2.4 Information Security Initiative Defense Capability Needs to be Further Improved Agricultural product electronic commerce management information system is a large scale, strong business dependence and the operation of complex adaptive system. No matter which part of the 
problem, it is likely to affect the overall function, resulting in the overall management of the information system failure. At the same time, along with the further advance of the electronic commerce construction of agricultural products, the characteristics of intelligence and information are becoming increasingly obvious. Due to the e-commerce of agricultural products and the service object of the two-way interaction further strengthen, intelligence gathering and terminal equipment usage is increased, and the intranet information and intelligent equipment secure access and data communications security issues become more and more important. Therefore, the demand for two-way intelligent terminal equipment led to the management of the risk of information management, and increase the risk management of the management of information management, is the construction of agricultural products e-commerce management information platform.

\section{Key Points of Management Information Platform of County Agricultural Products Electronic Commerce Based on Precision Poverty Alleviation}

Management of e-commerce of agricultural products to improve the efficiency of the park to help agricultural products e-commerce more comprehensive and more rapid analysis contained in a large number of data information and the law plays an important role, therefore the e-commerce of agricultural products should increase efforts to control data, pay attention to all kinds of data analysis and research, park information security enhancements, and efforts to improve decision analysis. The key points of the construction of the information platform for the management of agricultural products e-commerce in our country should include the following aspects:

\subsection{Improve the Ability for Analysis and Decision Making}

To improve the analysis of decision-making ability is mainly manifested in the following aspects: first, to increase the information storage capacity, the material flow, information flow and capital flow data are stored effectively; second, to meet the needs of business sectors and all levels of management decision-making, construction can cover all business sectors, the analysis system of each management level, development research the analysis model is more practical; third, improve the capability of data integration, build a data management platform to cover the entire e-commerce of agricultural products and agricultural products e-commerce public information model, realize the seamless transfer to agricultural e-commerce data, build a standard data management system, to improve the accuracy of and timeliness of data, improve the computing ability in real time, so that the data can be achieved online analysis, timely response With the request; the fourth, and comprehensively improve the data centers and structured data, spatial data and non structured data, real-time data storage and computing power, the information network extended to every information collection, the data transmission ability has been greatly improved; fifth, realize the data further use, must make service in agricultural product electronic commerce investment planning optimization, problem analysis and positioning, response capacity, park operation mode optimization and equipment condition evaluation effectively meet, this also let e-commerce of agricultural products in normal and orderly operation of strong protection $^{[3]}$.

\subsection{Achieve Business Integration at Different Stages}

To achieve business integration is mainly reflected in the following aspects: first, in accordance with the construction of integrated asset life, customer all-around, whole process of energy business lines to expand more logistics business, reached between each link of agricultural products e-commerce business integration; second, strengthening the management of information between the region and strengthen the production control area let the data integration, management information and production control information security two-way flow; third, the e-commerce of agricultural products within the scope of information sharing, as far as possible to meet the business needs analysis and decision making; fourth, construction of integrated information service platform, information standards and management capabilities continue to improve, and meet more depth the vertical integration and horizontal integration of information needs; fifth, to conduct a comprehensive 
monitoring of business processes, and expand the way of information And channels, so that mobile operations and mobile office can be more flexible and fast to interact with ${ }^{[4]}$.

\subsection{Information Security Protection}

The construction and communication technology and information technology of County agricultural products electronic commerce management information platform can not be separated, and the traditional agricultural products e-commerce security measures have been severely tested. Due to the increasing number of information automation equipment's and communication equipment's, the security problems of transportation, storage, loading and unloading, logistics finance, real estate and so on have become more complicated. With the further popularization of the intelligent and information of agricultural products e-commerce management, the realization of the interactive between park enterprises and agricultural products e-commerce, network boundary began to slowly extend to the user and intelligent equipment. So, it should be in time to build a set of agricultural products, e-commerce information and agricultural products, such as electronic commerce control and other comprehensive intelligent agricultural products e-commerce security system ${ }^{[5]}$.

\section{The Overall Planning of Management Information Platform of County Agricultural Products Electronic Commerce Based on Precision Poverty Alleviation}

The development process of electronic commerce of agricultural products is also the process of the deepening of information technology. The e-commerce of agricultural products through the reasonable, efficient, specific and comprehensive approach to data collection, processing and transmission of co-ordination of information resources, and ultimately the unification of e-commerce of agricultural products in all aspects. In the case that the effective protection of agricultural products e-commerce assets, and promote the safety and management level of agricultural products.

The organic combination of the information management of collaborative platform can realize the information transmission, information storage, information processing and other functions, management information model can very good to focus resources and overall standardized management model, and allocating information in accordance with the requirements of, to use the department to establish a resource virtualization, safe and reliable, the management level high operating environment. In the construction of the information platform, the data transmission, information storage and information processing capabilities of the platform are improved, and the depth of the information is fully excavated, and the coverage of the information is enlarged.

\subsection{Construction of the Information Network Center}

The intelligent work of the electronic commerce of agricultural products need to have a lot of data information, on the basis of information collection, transmission, analysis and processing, but also has a strong stability of the communication network. Intelligent equipment through the communication network for data processing, and can identify the operation process of the problem, and the alarm. In terms of network requirements, the need to expand the coverage area of the network to the user, so as to improve the overall and reliability of information. In the construction of agricultural product electronic commerce management information platform, the information network should be classified according to the grade. Need to acquire all kinds of knowledge in the construction of management information platform, to create information security of agricultural products in e-commerce environment, promote intelligent agricultural e-commerce platform for the management of clothing, and on the basis of information security protection built the wall to realize the information door. In the process of construction of management information platform, the first to improve the reliability of the information network as a key, which requires increased some network information channel, build a network of secondary and tertiary level, forming a three-dimensional network framework.

\subsection{Construction of Data Processing Center}

Through the collection of electronic commerce of agricultural products, some of the operation data and equipment working state, specific analysis, as a basis for the intelligent management and 
operation of agricultural products e-commerce to provide effective basis. In the construction of the database, expand information storage space, to reach the maximum storage volume of agricultural products e-commerce running state and running status of equipment, enterprise operating state, agricultural products e-commerce data storage state, but also improve the data analysis ability

\subsection{Construction of the Information Display Center}

The electronic commerce of agricultural products provides a platform for information planning, which lays the foundation for the dissemination of information. Broaden the way of information browsing and performance, providing mobile terminals, windows and screen terminals and other Internet sharing and access. Meet the diverse forms of visualization, multidimensional performance, and virtual reality and so on. Focus on browsing and search to make it more intelligent, professional, unified and standardized. Use at home and abroad leading man-machine communication, three-dimensional rendering of the 3D professional technology, finally realizes the management, operation and decision making of real, so as to further meet the user experience, enhance the operational efficiency of the park, broaden the professionals and users with various information browsing, to achieve stable and reliable information, to provide services for application management, decision.

\section{Conclusions}

In general, according to the actual situation of agricultural products e-commerce management, and gradually promote the implementation of integrated information platform, information security, work and maintenance of the revised standard, and so on. Innovative information technology methods, and constantly improve the key data of agricultural products, electronic commerce review, audit, dynamic publishing, business inquiries, equipment operation and maintenance capabilities, such as the operation of the control force. In the agricultural product electronic commerce overall information system framework based on the idea guide agricultural product electronic commerce information management work carried out fully guarantee the information in the process of precise poverty support and management control.

\section{Acknowledgement}

This work was supported by the grants from Hubei Provincial Collaborative Innovation Centre of Agricultural E-Commerce (under Construction) (Wuhan Donghu university research [2015] No. 11 Document)。

\section{References}

[1] Jesse James Garrett. The Elements of User Experience: User-Centered Design for the Web, California: New Riders Publishing, 2003.

[2] H. M. Have. A Semi-Automatic Method to Ontology Design by Using FCA, Proceedings of the 2nd International CLA Workshop, Ostrava, 2004.

[3] Haul Lee, W hang. Winning the Last Mile of E-Commence, Mc Grew Hill Companies, Inc, 2002.

[4] Gourde. Global Logistics Management: a Competitive Advantage for the New Millennium, Black Publication, 2002.

[5] Chun S H, Kim J C. Pricing Strategies in B2C Electronic Commerce: Analytical and Empirical Approaches, Decision Support Systems, Vol.40 (2005) No.2, pp: 375-388. 